\title{
Affective Spatial Compatibility Task (AffSCt): Theory and Applications
}

\author{
Erick Francisco Quintas Conde ${ }^{1}$ \\ Departamento de Psicologia da Universidade Federal de Pernambuco, Recife, \\ Pernambuco, Brasil \\ Elton H. Matsushima \\ Departamento de Psicologia da Universidade Federal Fluminense, Rio de Janeiro, \\ Rio de Janeiro, Brasil \\ Nelson Torro-Alves \\ Departamento de Psicologia da Universidade Federal da Paraíba, João Pessoa, \\ Paraiba, Brasil \\ Mikael Cavallet \\ Departamento de Psiquiatria da Universidade de São Paulo, São Paulo, São Paulo, Brasil \\ Fernanda Jazenko \\ Departamento de Neurociências da Universidade Federal Fluminense, Rio de Janeiro, \\ Rio de Janeiro, Brasil \\ Roberto Sena Fraga Filho \\ Programa de Pós-Graduação em Neurociências da Universidade Federal Fluminense, \\ Rio de Janeiro, Rio de Janeiro, Brasil \\ Universidade Estácio de Sá, Rio de Janeiro, Rio de Janeiro, Brasil \\ Luiz G. Gawryszewski \\ Programa de Pós-Graduação em Neurociências da Universidade Federal Fluminense, \\ Rio de Janeiro, Rio de Janeiro, Brasil
}

\begin{abstract}
Emotional stimuli are processed very efficiently, influencing physiological and behavioral responses as well as attention, perceptual processes and sensory-motor integration. In a previous work, we introduced a new paradigm, the Affective Spatial Compatibility task (AffSCt), to study whether the affective valence of the stimulus influences spatial compatibility effects. By using figures of soccer players of Favorite and Rival Teams as positive and negative valence stimuli, we found a normal Spatial Compatibility effect for the Favorite team and a reversed one for the Rival team. Here, we analyzed the time course of inhibitory and facilitatory effects of emotional valence by the Vincentization method. We found that for Favorite team, the facilitatory effect for the compatible condition, as compared to the incompatible one,
\end{abstract}

Mailing address: Centro de Filosofia e Ciências Humanas, Departamento de Psicologia, Universidade Federal de Pernambuco, Av. da Arquitetura, s/nº, Cidade Universitária, Recife, PE, Brasil 50670-901. E-mail: psicoerick@yahoo.com.br, eh.matsushima@gmail.com, nelsontorro@yahoo.com.br, mklcv@hotmail.com, fernandajzk@yahoo.com.br, senaff@gmail.com and gawryszewski@gmail.com

Financial support: Coordenação de Aperfeiçoamento de Pessoal de Nível Superior (CAPES), Fundação de Amparo à Pesquisa do Estado do Rio de Janeiro (FAPERJ), Conselho Nacional de Desenvolvimento Científico e Tecnológico (CNPq), Pró-Reitoria de Pesquisa, Pós-Graduação e Inovação-Universidade Federal Fluminense (PROPPi-UFF), UFF. CNPq (processos 450588/2009-2; 309544/2009-2; 483611/2009-3; 455353/2012-3; 312189/2012-5; 478834/2013-6; 479793/2013-1); CAPES FAPERJ (processos 110.079/2013; E-26/101.958/2010: E-26/101.061/2011; FOPESQ/UFF; PROPPi/UFF; FAPESP (processo 2011/09946-9). 
increases as a function of the reaction time. In contrast, for Rival team, an opposite trend was found, in which inhibitory effect becomes stronger for slower responses. We suggest that AffSCt is a powerful technology for investigating approach/avoidance effects and that it may be useful for diagnosing and following up the treatment of affective and behavioral disorders, such as anxiety, panic and ADHD. Potential applications in social psychology and consumer studies are also considered.

Keywords: Mental chronometry, affective valence, spatial compatibility, approach/avoidance, emotion.

\section{Tarefa de Compatibilidade Espacial Afetiva (TCEA): Teoria e Aplicações}

\section{Resumo}

Os estímulos emocionais são processados de forma muito eficiente, influenciando as respostas fisiológicas e comportamentais, bem como a atenção, a percepção e a integração sensório-motora. Em um trabalho anterior, propusemos um novo paradigma, a Tarefa Afetiva de Compatibilidade Espacial (AffSCt), para estudar se a valência afetiva do estímulo influenciaria os efeitos de compatibilidade espacial. Ao usarmos figuras de jogadores de futebol dos times Favorito e Rival como estímulos de valência positiva e negativa, respectivamente, encontramos um efeito de compatibilidade espacial normal para o time Favorito e um invertido para o time Rival. No presente trabalho, foi analisado o desenvolvimento temporal dos efeitos inibitórios e facilitatórios da valência emocional pelo método da Vincentização. Descobrimos que, para o time Favorito, o efeito facilitatório na condição compatível em relação à incompatível aumenta em função do tempo de reação. Em contraste, para o time Rival, uma tendência oposta foi encontrada, em que o efeito inibitório se torna mais forte para as respostas mais lentas. Sugere-se que a AffSCt é uma tecnologia poderosa para investigar comportamentos de aproximação/ afastamento, podendo ser útil na avaliação diagnóstica e acompanhamento terapêutico de transtornos emocionais e comportamentais, como o de ansiedade generalizada, síndrome de pânico e transtorno do déficit de atenção/hiperatividade. Também são consideradas as aplicações potenciais em psicologia social e estudos de consumidor.

Palavras-chave: Cronometria mental, valência afetiva, compatibilidade especial, aproximação/afastamento, emoção.

\section{Tarea de Compatibilidad Espacial Afectiva (TCEA): Teoría y Aplicaciones}

\section{Resumen}

Los estímulos emocionales se procesan de manera muy eficiente e influyen en las respuestas fisiológicas y de comportamiento, así como en la atención, la percepción y la integración sensorio-motora. En un trabajo previo, que presentó un nuevo paradigma, la tarea afectiva de compatibilidad espacial (AffSCt), para estudiar si la valencia afectiva de los estímulos influyen en los efectos de la compatibilidad espacial. Mediante el uso de las figuras de los jugadores de fútbol de los equipos favorito e rival como estímulos positivo y negativo de valencia, respectivamente, se observó un efecto ordinario de compatibilidad espacial para el equipo favorito y un efecto invertido para el equipo rival. En este estudio, hemos examinado la evolución temporal de los efectos inhibitorios y facilitatorio de la valencia emocional por el uso de la Vincentización. Hemos encontrado que, para el equipo favorito, el efecto facilitatorio aumenta para la condición compatible, respecto la incompatible, con el tiempo de eacción. En contraste, para el equipo rival, una tendencia inversa se encontró, en el que el efecto inhibidor se vuelve más fuerte para las respuestas más lentas. Se sugiere que AffSCt es una poderosa tecnología para investigar los 
comportamientos de aproximación/retirada que puede ser útil para diagnosticar y seguir el tratamiento de trastornos afectivos y conductuales como ansiedad, pánico y déficit de atención/trastorno de hiperactividad. También son consideradas aplicaciones potenciales del método en la psicología social y en los estudios de consumo.

Palabras clave: Cronometría mental, valencia afectiva, compatibilidad espacial, aproximación/retirada, emoción.

Emotional stimuli are considered relevant biologically sources of information, being processed very quickly and efficiently (Farah, Wilson, Drain, \& Tanaka, 1998; Leppänen \& Hietanen, 2004; Usakli, Susac, \& Gürkan, 2011). This advantage in emotional processing plays an important role in the apprehension of menacing or positive information from the environment (Bayle, Schoendorff, Hénaff, \& Krolak-Salmon, 2011). Studies have shown that an emotional stimulus can be processed with or without awareness and can influence physiological and behavioral responses (Merikle, Smilek, \& Eastwood, 2001; Tamietto \& de Gelder, 2010). For instance, in Affective Blindsight, patients with damages in the striate cortex cannot consciously perceive a visual stimulus, however, they are capable of discriminating their emotional content (de Gelder, Vroomen, Pourtois, \& Weiskrantz, 1999).

Additionally, Eastwood and Smilek (2005) suggested that the non-conscious perception of the affective valence of emotional facial expressions has three functions: to elicit emotional responses in the observer; to influence the conscious experience of other stimuli; and to influence social communication. When participants observe negative or threatening stimuli, they may present autonomic involuntary changes, marked by the activation of the sympathetic system, deactivation of the parasympathetic system and freezing reactions. Such changes lead to a state of physiological arousal that includes larger skin conductance responses, alterations in hormonal levels, altered activity in amygdala, and so on (Eastwood \& Smilek, 2005). Those autonomic changes are more pronounced in individuals with anxiety disorders, such as panic and phobias (Lang \& McTeague, 2009; Roth, 2005).

Even for short-time course processes, such as those studied in reaction time experiments, the valence of the stimulus affects responses, which might be associated to approach and avoidance behaviors (see Alves, Fukusima, \& Aznar-Casanova, 2008; Markman \& Brendl, 2005; Proctor \& Zhang, 2010, for reviews). For instance, people are faster in making approach responses to positive stimuli and avoidance responses to negative stimuli than to the opposite mapping (Chen \& Bargh, 1999; de Houwer, Crombez, Baeyens, \& Hermans, 2001; Müsseler, Aschersleben, Arning, \& Proctor, 2009; Y. Zhang \& Proctor, 2008).

Historically, two tasks have been employed for analyzing the effects of the spatial correspondence between the side of the stimulus and the side of the response key (see Gawryszewski et al., 2006; Riggio, Gawryszewski, \& Umiltá, 1986; for reviews). In a spatial compatibility task, the correct response is selected according to the spatial location of the stimulus. When the stimulus side coincides with the side of the key (compatible condition), the Manual Reaction Time (MRT) is about $50 \mathrm{~ms}$ shorter than when the stimulus and key are located on opposite sides (incompatible condition; Anzola, Bertoloni, Buchtel, \& Rizzolatti, 1977; Gawryszewski et al., 2008; Pellicano et al., 2010; Proctor \& Vu, 2006; Riggio et al., 1986; Umiltá \& Nicoletti, 1990; Wallace, 1971). In contrast, in the Simon task (see Hommel, 2011, for a review), the response selection is based on non-spatial stimulus features, such as its form or color. Although the spatial location of the stimulus is an irrelevant feature for the response selection, when the sides of the stimulus and the response key are the same (corresponding condition), the MRT is shorter (about 20-30 ms) than when they are located on opposite sides (Lu \& Proctor, 1995; Pellicano et al., 2010; Proctor \& Vu, 2006; Rubichi \& Nicoletti, 2006). Furthermore, it has been shown that both the spatial compatibility and the Simon effects may be influenced by the affective 
valence of the stimulus and that stimulus valence is linked with avoidance/approach behaviors (Chen \& Barg, 1999; Markman \& Brendl, 2005; Proctor \& Zhang, 2010). For instance, Chen and Bargh (1999) used a lever that had to be pushed away (avoidance) or pulled toward (approach) the participant's body according to the affective valence of a centrally presented word. Participants were randomly assigned to one of two experimental conditions. In the incongruent condition, the participants were instructed to push the lever forward with their hand as quickly as possible when they judged the word as good and to pull the lever toward them when they judged the word as bad. In the congruent condition, participants were given the opposite instructions: pull the lever if the word is positive and push the lever if the word is negative. They found that automatic valence evaluation results in faster approach responses to positive valence stimuli and faster avoidance responses to negative valence stimuli. These results were supported by Markman and Brendl (2005) and Proctor and Zhang (2010).

In a previous paper (Conde et al., 2011), we proposed a modified version of the spatial compatibility task in order to study the influence of affective valence of stimuli on the spatial compatibility effect. In this new paradigm that we called Affective Spatial Compatibility task (Af$\mathrm{fSCt}$ ), three tasks were combined: (a) the Spatial Compatibility task (which involves an explicit stimulus location code); (b) the Simon task (based on an implicit spatial location code of neutral stimuli), and (c) the Affective Simon task (which involves an implicit spatial location code for an affective stimulus). In that work, figures of soccer players from the volunteer's Favorite Team and its main Rival Team were the positive and negative valence stimulus, respectively. The selection of the correct response was based both on the spatial location and affective valence. More specifically, a compatible or an incompatible response was chosen according to the team depicted in the stimuli. In one block of trials, participants reacted with a compatible response to Favorite team stimulus, pressing a key on the same side of Favorite team stimulus; and with an incompatible response to Rival team stimulus, pressing a key on the opposite side of Rival team stimulus. In the other block, a reverse code was used. We found an ordinary Spatial Compatibility effect for the Favorite team, but a reversed one for the Rival team (i.e., the incompatible responses were faster than the compatible ones). We proposed that this modulation was a result from approach and avoidance behaviors towards Favorite and Rival team, respectively.

Results of Conde et al. (2011) opened up an important applied research field, since the AffSCt may be a methodology capable of identifying opposite patterns of affective valence. For instance, AffSCt can be used to explore differential patterns of affective valence effects in non-clinical groups as well as in psychiatric and neurological patients, afflicted by disorders such as the Attention Deficit/Hyperactivity Disorder (ADHD) and Parkinson Disease (PD). The AffSCt involves multiple cognitive processes, such as response inhibition, selective attention, perceptual conflict, emotional processing and response execution, which could be differentially affected by emotional valence. For instance, an important characteristic of the ADHD is the difficulty to inhibit motor responses, and although executive functions have been extensively investigated in this disorder, the processing of emotional content was poorly explored. Evidences suggest ADHD patients' performance in tasks that require the identification of emotional expressions, especially negative ones, was reliably disturbed (for a review, see Herrmann, Biehl, Jacob, \& Deckert, 2010). Thus, for ADHD patients, it may be expected that their performance would be less affected by the negative emotional stimuli and that a strong spatial Stimulus-Response Compatibility (SRC) would appear for positive stimuli, due to their inability to inhibit motor responses. In parallel, PD is a neurodegenerative basal-ganglia disorder with severe motor symptoms and cognitive dysfunctions. More specifically, PD affects differentially the inhibitory processes of prepared responses in a modified go/no-go task with compatible and incompatible stimulus-response mapping according to the meaning of the stimuli. PD patients presented an unaffected performance in compatible response inhibition, but presented deficits in 
incompatible response inhibition. Scrutinizing those deficits, researchers found in the event related potentials (ERPs) that P3, usually associated to evaluation of successful motor inhibition, was specifically attenuated and delayed in the incompatible condition for PD patients (Beste, Dziobek, Hielscher, Willemssen, \& Falkenstein, 2009). Due to its methodological features, AffSCt might be an alternative task to reveal yet unexplored deficits in PD. Furthermore, differential performances in AffSCt of patients afflicted by other psychiatric disorders might improve our understanding of the cognitive impairments related to those disorders.

At this point, it is worth to mention that a very important tool to understand the behavioral deficits presented by ADHD and PD patients has been the distributional analyses (Ridderinkhof, Scheres, Oosterlaan, \& Sergeant, 2005; Wylie, Ridderinkhof, Bashore, \& van den Wildenberg, 2010). There are several tools available for distributional analyses (de Jong, Liang, \& Laubert, 1994; Ridderinkhof et al., 2005). The most common is made by ranking reaction time (RT) in temporal order (shorter to longer MRTs) for each experimental condition and then divided into five equal-size bins (quintiles). The RT mean in each quintile is calculated and the difference between incompatible minus compatible conditions show the effect size for each quintile. The ANOVA procedures verify whether the effect size changes or not as a function of RT temporal distribution. The typical pattern is that the difference in RT between the two conditions decreases from first to fifth quintiles (de Jong et al., 1994; Luce, 1986; Ridderinkhof et al., 2005).

De Jong et al. (1994) used delta plots in a particular variety of the Simon task to plot the effect size as a function of response speed and presume that the slopes between quintile points in delta plots for RT reflect the relative time course of two different types of activation: unconditional (direct, automatic) vs. conditional (indirect) activation. Positive and negative delta plot slopes may result from differential time courses of direct and indirect activations, although they may also result from intended or unintended manipulation of variability parameters (J. Zhang \& Kornblum, 1997).
Ridderinkhof et al. (2005) showed that this type of analysis might be very useful to explore specific mechanisms involved in the activation and suppression of responses during the performance of conflict tasks. They used Delta-plot and accuracy analyses to investigate cognitive deficits associated with ADHD. The data of 20 children with ADHD and 20 control healthy children were taken from a larger-scale study of the cognitive effects of methylphenidate therapy of ADHD, using an Eriksen flanker task as the behavioral measure. The distributional analyses of mean RT showed a pronounced leveling off in the positive-going delta plots for RT of control children than of children with ADHD (Ridderinkhof et al., 2005). The delta plots for control and ADHD children diverged only at the slower end of the RT distribution, whereas delta leveled off for control children occurred earlier than for ADHD. Based on the activation-suppression hypothesis (Ridderinkhof, 2002), the delta plot analysis indicates a better selective inhibition of responses on the Eriksen flanker task in normal control children in comparison to the ADHD children in which response inhibition operate slower (Ridderinkhof et al., 2005). These findings would not have been possible if only the overall performance had been analyzed.

The fMRI has allowed the identification of the brain activity associated to specific SRC task components. Greater activity has been found in frontal-parietal brain regions suggesting a common frontal-parietal network involved in the spatial coding of the spatial SRC effect. Response conflict or competition as observed in incompatible trials seems to be monitored by the anterior cingulate cortex (Schumacher, Cole, \& D'Esposito, 2007), while the dorsal premotor and the superior frontal and parietal cortex form a network representing the stimulus-response spatial coding in a body-centered map (Matsumoto, Misaki, \& Miyauchi, 2004). The dorsal prefrontal cortex and bilateral superior frontal gyrus have a significantly greater activation when responses are incompatible than compatible suggesting that these areas are involved in the selection of the appropriate response for external stimuli (Matsumoto et al., 2004; Schumacher et al., 2007; Schumacher \& D'Esposito, 
2002). Nonetheless, there are still few neuroimaging studies investigating the functionality of the structures involved in the SRC effect, and no reports regarding the brain activity when a spatial SRC task is performed with stimuli of different valences. This investigation is important to identify the brain areas and cognitive processes serving spatial and emotional responses selection supposed to be involved in the AffSCt.

In the present study, we extended the analysis reported in Conde et al. (2011), aiming to accomplish part of the enterprise of providing a complete description of the phenomena associated to AffSCt. In order to establish how the approach and avoidance responses are temporally produced in AffSCt, distributional analyses were applied on data. We also use the Favorite and Rival teams as stimuli in order to investigate how the stimulus affective valence influences the reaction time distribution in AffCTs. Taking into account the previous work of distributional analyses (de Jong et al., 1994; Luce, 1986; Ridderinkhof et al., 2005; J. Zhang \& Kornblum, 1997), we expected to find distinct patterns of the temporal distribution of facilitatory and inhibitory effects for Favorite and Rival stimuli.

\section{Methods}

\section{Participants}

Fourteen participants from the Universidade Federal Fluminense (UFF, Rio de Janeiro,
Brazil) community, aged between 19-30 years (eight males and six females) accomplished the experiments. All participants were right-handed verified by Edinburgh inventory (Oldfield, 1971), had normal or corrected-to-normal vision, and were not aware of the purposes of the experiment about the purposes of the experiment. A written informed consent form was obtained from all subjects, and the study was approved by the Institutional Ethics Commission of the UFF (Report 349/2010).

\section{Equipment and Apparatus}

The experiments were performed in a dimly lit and sound-proof cabin where participant sat in front of a monitor at a viewing distance of approximately $57 \mathrm{~cm}$. Responses were made on a computer keyboard using left (the letter "A") and right (the number " 6 " on the numerical keypad) keys in the horizontal dimension. The index fingers were used to produce the experimental responses. Stimuli were colored depictions of soccer players $\left(6.5^{\circ}\right.$ high $\times 1.5^{\circ}$ wide $)$ wearing the main uniform of the four most popular soccer teams of Rio de Janeiro (Figure 1). Stimuli were randomly presented at $6.0^{\circ}$ to the left or to the right of a centered fixation point. Presentation and response records were accomplished in E-Prime 2.0 suite. Continuous eye tracking ensured that participants kept gaze at fixation point (Eye Track System, Model 210 - Applied Science Laboratories).
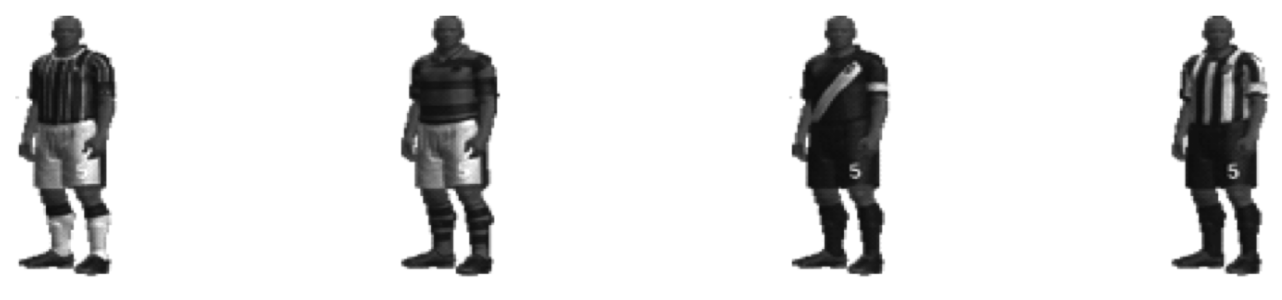

Figure 1. Depictions of soccer players from the four most popular teams of Rio de Janeiro, Fluminense, Flamengo, Vasco da Gama and Botafogo, respectively.

\section{Procedures}

Previously to the experimental session, participant completed a valence rating, ranking, in preference order, the four most popular soccer teams of Rio de Janeiro: Fluminense, Flamengo, Vasco da Gama, and Botafogo. The first and the 
fourth team, in order of preference, defined the Favorite and Rival soccer teams for each participant. So, for one participant, "Vasco da Gama" could be the Favorite team and "Botafogo", its main rival. For another participant, "Flamengo" might be the Favorite and "Fluminense" its main rival. This procedure selected the two stimuli for the AffSCt, the positive and negative valence stimuli, Favorite and Rival teams, respectively (Conde et al., 2011).

The experimental session has two counterbalanced blocks of 120 trials, each one preceded by a 40 -trials training block. In the first block, half of the sample was instructed to respond by pressing the key on the same side of the stimulus (compatible condition) for the Favorite team and by pressing the key on the opposite side of the stimulus (incompatible condition) for the Rival team. In the second block, the reverse mapping was instructed, the compatible condition for the Rival team and the incompatible condition for the Favorite team (Figure 2). The other half of the sample began with the compatible condition for the Rival team and incompatible condition for the Favorite team and, with the reverse mapping in the second block.

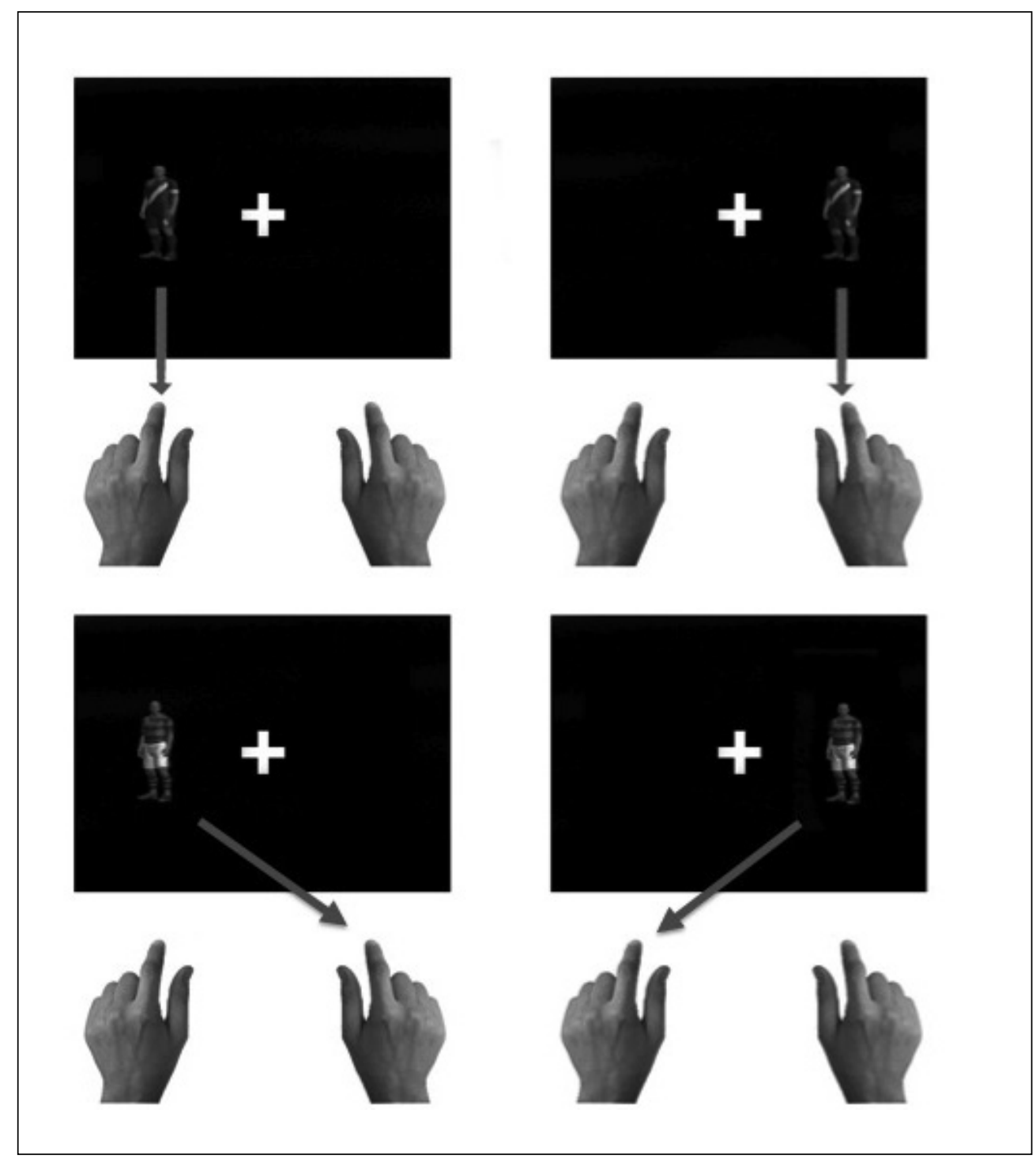

Figure 2. Examples of compatible and incompatible experimental conditions.

Note. Upper Panel: Compatible condition for a participant whose Favorite team was Vasco da Gama, he/she must press the key on the same side of the stimulus and the opposite key for the Rival team. Lower Panel: Incompatible condition for a participant whose Favorite team was Flamengo, he/she must press the opposite key to the Favorite team and the same side key to Rival team. 


\section{Analysis}

The correct MRTs were ranked in temporal order (shorter to longer MRTs) for each experimental condition and then divided into five equal-size bins (quintiles). After this Vincentization procedure (de Jong et al., 1994; Proctor, Yamaguchi, Zhang, \& Vu, 2009), the mean MRT of each quintile was submitted to ANOVA analyses, with Preference (Favorite and Rival), Compatibility (Compatible and Incompatible) and Bin (the five quintiles of MRT) as withinsubject factors. Data analyses were conducted with the software Statistica 6.0.

A Delta-plot analysis comparing the Compatibility effect for each bin was also accomplished, computing the differences between incompatible and compatible means for each quintile. These differences represent the magnitude of the compatibility effect for each quintile and were subsequently submitted to an ANOVA, with Preference, Compatibility and Bin as within-subject factors. The significance level considered was $p<.05$.

\section{Results}

The first ANOVA showed reliable effects for main factor $\operatorname{Bin}, F_{(4,52)}=48.078, p<.001$ and interactions between Preference and Compatibility factors, $F_{(1,13)}=6.491, p=.024$, between Compatibility and Bin factors $F_{(4,52)}=2.593, p=$ .047 and also the most relevant three-way interaction between all factors Preference, Compatibility and Bin, $F_{(4,52)}=3.320, p=.017$ (Figure 3).

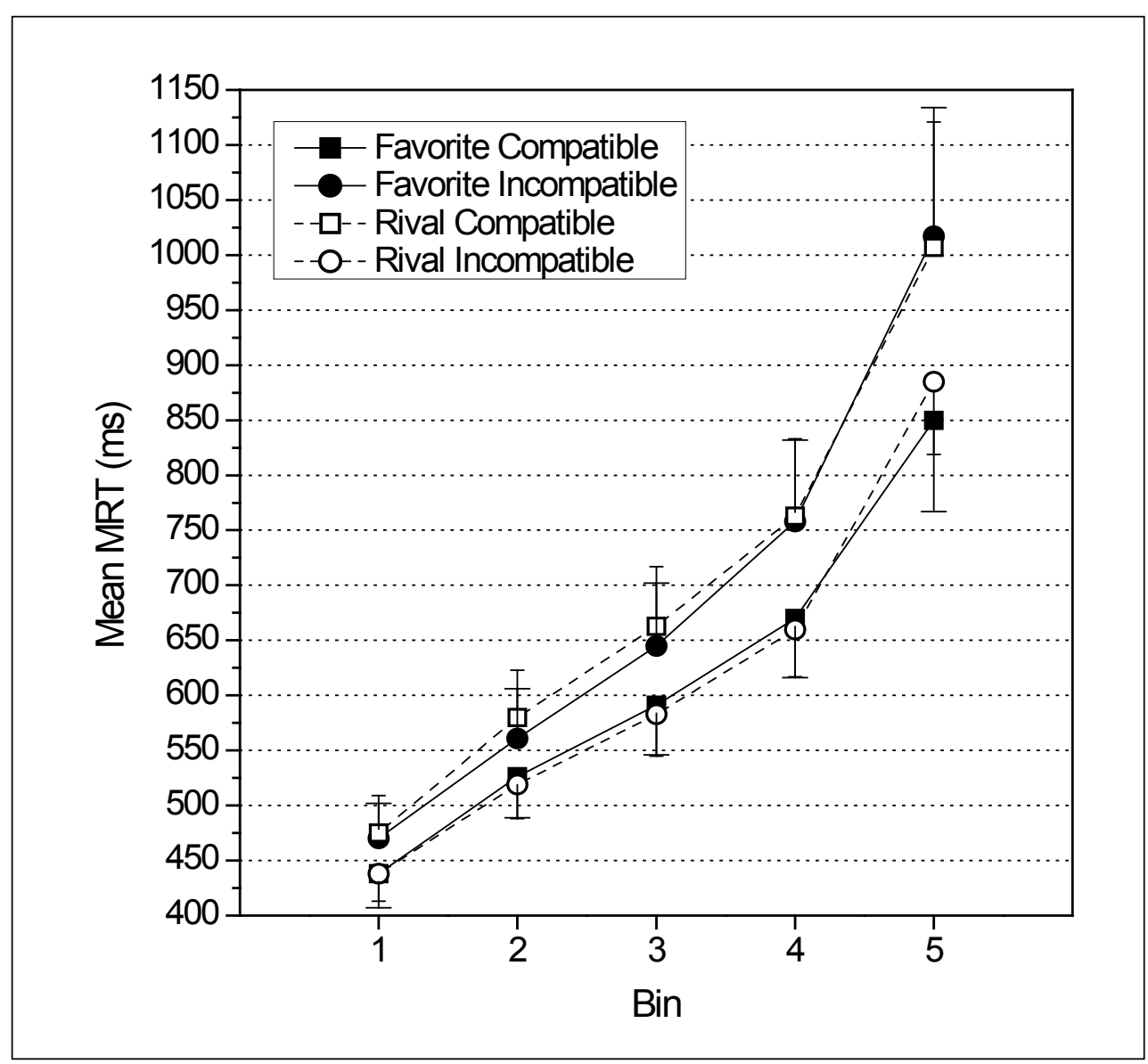

Figure 3. Mean MRT, in milliseconds, as a function of bin, for Favorite and Rival stimuli in incompatible and compatible conditions.

Note. Filled figures and continuous lines represent MRT for Favorite stimuli, and open figures and dashed lines, for Rival stimuli. Squares represent Compatible conditions and circles, Incompatible conditions. Vertical bars represent standard errors of mean (SEM), which those with larger caps represent MRT for Favorite stimuli, and they are depicted in only one direction for visualization purposes. 
Further analyses on the three-way interaction revealed asymmetries between Favorite and Rival on the temporal distribution of the differences between compatible and incompatible conditions. There is a significant interaction between Preference and Compatibility main factors showing that, for Favorite team, the compatible responses $(615 \mathrm{~ms} \pm 239 \mathrm{~ms})$ were faster than incompatible ones $(690 \mathrm{~ms} \pm$ $322 \mathrm{~ms}), F_{(1,13)}=24.420, p<.001$, and for Rival, there is an inversion of the spatial compatibility, incompatible responses $(617 \mathrm{~ms} \pm 219 \mathrm{~ms})$ being faster than compatible ones $(698 \mathrm{~ms} \pm 311$ $\mathrm{ms}), F_{(1,13)}=7.328, p=.018$. For Favorite, the expected spatial compatibility effect appears only for the slower MRT bin, $F_{(1,13)}=75.546$, $p<.001$. Despite the absence of significant differences on the other bins (Figure 4), one may observe a trend of increasing effect size with slower responses. On the other hand, for Rival team, the inversion of spatial compatibility effect has already occurred in the first quintile, $F_{(1,13)}=4.727, p=.049$, for incompatible condition (438 $\mathrm{ms} \pm 92 \mathrm{~ms}$ ) yielded responses 37 $\mathrm{ms}$ faster than compatible condition (475 $\mathrm{ms} \pm$ $126 \mathrm{~ms})$. For the subsequent quintiles, the effect rose up to the fourth quintile. In the second quintile, incompatible responses $(519 \mathrm{~ms} \pm 116$ $\mathrm{ms})$ were $61 \mathrm{~ms}$ faster than compatible $(580 \mathrm{~ms}$, $\pm 160 \mathrm{~ms}), F_{(1,13)}=9.914, p=.008$; in the third $(583 \mathrm{~ms} \pm 143 \mathrm{~ms}), 80 \mathrm{~ms}$ faster $(663 \mathrm{~ms} \pm 203$ $\mathrm{ms}), F_{(1,13)}=10.750, p=.006$; and in the fourth $(660 \mathrm{~ms} \pm 162 \mathrm{~ms}), 103 \mathrm{~ms}$ faster $(763 \mathrm{~ms} \pm$ $263 \mathrm{~ms}), F_{(1,13)}=7.481, p=.017$. However, in the fifth quintile, the longer group of MRTs, the inversed compatibility effect (-122 ms) was not significant, $F_{(1,13)}=3.704, p=.076$ (Figure 3).

The ANOVA on delta plot data, based on the difference between incompatible and compatible RT for each bin, with Preference and $B i n$ as within-subjects factors, revealed significant effects for both main factors Preference, $F_{(1,13)}=6.491, p=.024$, and $\operatorname{Bin}, F_{(4,52)}=2.593$, $p=.047$, as well as for their interaction, $F_{(4,52)}=$ $3.320, p=.017$. This latter significant effect was thoroughly investigated by planned analyses, which revealed significant differences between the compatibility effects for Favorite and Rival stimuli from the second bin up to the longer one, the fifth bin. More specifically, the compatibility effects were 35 and $-61 \mathrm{~ms}$ for second bin, $F_{(1,13)}=4.922, p=.045 ; 55$ and $-81 \mathrm{~ms}$ for third bin, $F_{(1,13)}=6.698, p=.023 ; 167$ and -103 for fourth bin, $F_{(1,13)}=6.209, p=.027$; and 168 and $-122 \mathrm{~ms}$ for fifth bin, $F_{(1,13)}=5.128, p=.041$ (Figure 4).

\section{Discussion}

In the present study, we extended our previous work about the influence of the affective valence on spatial compatibility effect (Conde et al., 2011), investigating the time course of facilitatory and inhibitory effects elicited by the presentation of figures of the Favorite and Rival soccer team players as positive and negative affective stimuli, respectively.

Recently, Proctor (2013) criticized Conde et al. (2011) interpretations, pointing that we used a mixed-rule task in which compatible and incompatible conditions occurred together within a block of trials. He showed that, when Favorite stimuli signaled compatible and Rival the incompatible mapping-rule, the MRTs are shorter than in the opposite situation. Conde et al. (2014) replicated these results and showed that the emotional effect vanished when neutral soccer stimuli (fake soccer team) were used. The results described in the current paper showed different patterns of temporal distribution for each affective valence (favorite and rival stimuli), even sharing the fact that compatible and incompatible practices were made in different blocks of trials.

Using Vincentization methodology (de Jong et al., 1994; Proctor et al., 2009), we found that, for Favorite team, the difference between the Incompatible and Compatible RT increases as function of the MRT. In contrast, for Rival team, an opposite trend was found, in which the difference between the Incompatible and Compatible RT decreases (becoming more negative or having a negative slope) as function of the MRT. These results indicate that, as MRT becomes longer, there is an increase of the facilitatory and inhibitory effects for Favorite and Rival teams, respectively. 
As previously mentioned, the AffSCt combines in a single test, three commonly employed tasks for studying spatial S-R effects: Spatial Compatibility, Simon and Affective Simon task, whose effects are based on: an explicit stimulus location code; an implicit spatial location code of neutral stimuli; and an implicit spatial location code for an affective stimulus, respectively. As corollary, in AffSCt, distinct automatic and voluntary components, that are present in each of the three S-R mentioned tasks, would occur simultaneously in a single task.

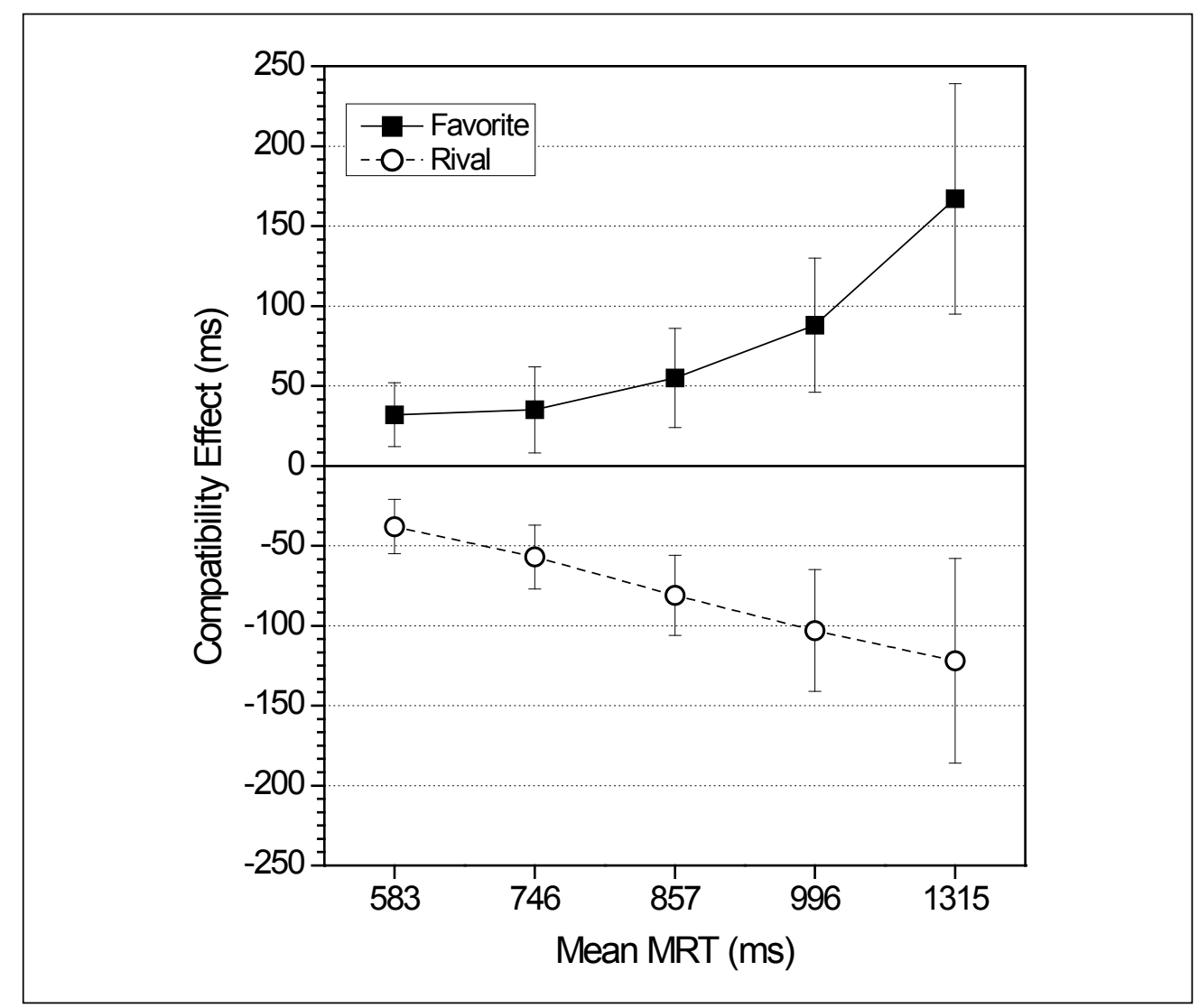

Figure 4. Delta plot analysis depicting the magnitude of the compatibility effects (difference between incompatible and compatible MRT), in milliseconds, as a function of mean MRT, in milliseconds.

Note. Filled squares and continuous line represent Favorite condition; and open circles and dashed line, Rival condition. Vertical bars represent standard error of means.

The RT distribution analyses, Vincentization and Delta plot (de Jong et al., 1994; Luce, 1986; Ridderinkhof et al., 2005; Wylie et al., 2010; J. Zhang \& Kornblum, 1997) allowed a description of the time course of the facilitatory and inhibitory components which are present in each one of the tasks that are combined in AffSCt. For the classical Spatial Compatibility task (Anzola et al., 1977; Gawryszewski et al., 2006; Gawryszewski et al., 2008; Riggio et al., 1986), the difference between incompatible and compatible RT (Compatibility effect) increases as function of RT.
In contrast, in the Simon task along the horizontal dimension, the difference between non-correspondent and correspondent RT (magnitude of the Simon effect) decreases for longer RT. There are two main interpretations for the reduction of the Simon effect. The first one emphasizes facilitation due to an automatic orienting of attention toward the side of the peripheral stimulus. This facilitation is presumed to be short-lived, decreasing for longer RT, resulting in a smaller, null or even in an inverted Simon effect for longer MRT (see Proctor et al., 2009, for a review). The other proposal did not deny 
this automatic effect, but emphasizes the inhibitory component which is generated simultaneously to the facilitatory one in order to suppress the incorrect response in non-correspondent trials (see Ridderinkhof et al., 2005; Wylie et al., 2010, for review). The last interpretation has been supported when the RT distribution is analyzed (in particular, delta plots for both response speed and accuracy) and the Simon effect is computed as a function of RT. According to this proposal, suppression mechanisms need some time to become effective. Thus, slower responses on correspondent trials would be more affected by the suppression since more time was available for the build-up of suppression to refrain the incorrect activation (for a review, see van den Wildenberg et al., 2010).

Neuroimaging studies using RT distribution-analyses and fMRI techniques to examine the interplay between response activation and response inhibition in modified Simon tasks have shown the activation of specific areas involved in this suppression mechanism (Forstmann, Jahfari, et al., 2008; Forstmann, van den Wildenberg, \& Ridderinkhof, 2008). The results of Forstmann, Jahfari, et al. (2008) revealed that the steeper slope of positive-going accuracy functions (accuracy plotted as a function of response speed) of incongruent trials covaried with enhanced pre-supplementary motor area (pre-SMA) activation only for the first segment of the function (i.e., for the segment of fast RTs). Furthermore, selective response suppression as measured with the slopes of different segments of the delta plots of RTs, and entered as covariates in the fMRI analyzes, revealed a covariation between the negative-going delta slope of the slowest segment of the RT distribution of incongruent trials with the activation of the right inferior frontal cortex (rIFC). The authors concluded that the pre-SMA is recruited to resolve the conflict between responses and select the appropriate response, and that the activity in the right IFC is related to the suppression of the incorrect response in the Simon task (Forstmann, Jahfari, et al., 2008). Similar activation of the rIFC was obtained in Forstmann, van den Wildenberg, et al. (2008), but adding a strong correlation between functional and structural characteristics of the rIFC and slowest segment of the RT distributions related to the selective response mechanism.

These results are in agreement with a common frontal-parietal network involved in the processing of the spatial coding and selective inhibition in conflict tasks, and reveal that distributional RT analyzes associated to neuroimaging data can be useful to scrutinize the selective inhibition mechanisms engaged in conflict tasks such as the AffSCt. Beyond the pre-SMA, the dorsal prefrontal cortex and the bilateral superior frontal gyrus might be also involved in the selection of the appropriate response as revealed by significant greater activation when responses are incompatible than when compatible (Matsumoto et al., 2004; Schumacher et al., 2007; Schumacher \& D'Esposito, 2002).

Finally, we suggest that the Affective Spatial Compatibility task (AffSCt) may be a powerful tool for investigating approach/avoidance effects and that this experimental procedure may be applied to evaluate individuals with anxiety disorders, such as generalized anxiety disorder, phobias and panic disorders (Lang \& McTeague, 2009; Roth, 2005). A possible study would be to compare patients with anxiety disorders and control volunteers in tasks of recognition of the different basic facial emotions (happiness, sadness, fear, anger, disgust and surprise). Likewise, participants could be asked to respond to positive, negative and neutral non-facial stimuli, such as those found in International Affective Picture System (IAPS; Lang, Bradley, \& Cuthbert, 2008). If negative stimuli elicit avoidance behaviors, one may expect that phobic individuals would present an inversion of spatial compatibility effects of larger magnitude, when compared to controls. Therefore, the present findings can contribute to the development of new experimental protocols, which would be useful to assess phobic and anxiety symptoms as well as to measure the efficiency of different therapeutic treatments. One of the advantages of the AffSCt is that it captures the automatic and involuntary processes, which also contribute to the onset and maintenance of anxiety disorders, in addition to conscious cognitive factors (Friedman, Thase, \& Wright, 2008). Therefore, AffSCt could complement the application of symptom scales (e.g., 
Beck Depression Inventory), contributing to a thorough comprehension of patient's anxiety disorder.

Beyond clinical applications, the AffSCt would also find utility in other applied areas of Neurosciences, as the new field of neuromarketing. According to Ariely and Berns (2010), most of the contributions in neuromarketing research are made using complex and advanced neuroimaging procedures to determine the effect of a marketing strategy in the consumer's brain. However, Ouazzani-Touhami et al. (2011) proposed that one of the challenges for the scientific progress in neuromarketing is the development of more accessible techniques and technologies. This is where one must consider the AffSCt as a potential tool for neuromarketing research, for its accessible and simple experimental apparatus. It has been shown that AffSCt provide access to the implicit patterns of preference in comparing the motor responses for two stimuli and it may be a useful methodological tool for neuromarketing investigations. Another advantage of AffSCt for neuromarketing studies would be that this experimental protocol would provide information about a complete psychological process, from sensorial coding up to decision making, as opposed to the more expensive and less informative methods of functional brain imaging.

As we can see, the AffSCT is an important technological innovation in neuropsychology because it allows to: (a) identify facilitatory and inhibitory effects with a simple methodology that evaluates approach and avoidance behaviors in normal people; (b) compare the effects of the innate (as emotional faces) and learned affective valence (as preference for soccer teams); (c) investigate the correlations between behavioral measures and brain activity (as fMRI - that is being studied by Cavallet et al., 2014, on an ongoing project -, evoked potentials, and EEG); (d) determine patterns of facilitatory and inhibitory reactions presented by individuals with mental disorders. In sum, the tool can be considered as a potential innovation on assessment in basic psychology as well as in neuropsychological science.

\section{References}

Alves, N. T., Fukusima, S. S., \& Aznar-Casanova, J. A. (2008). Models of brain asymmetry in emotional processing. Psychology \& Neuroscience, 1(1), 63-66. doi:10.1590/S198332882008000100010

Anzola, G. P., Bertoloni, G., Buchtel, H. A., \& Rizzolatti, G. (1977). Spatial compatibility and anatomical factors in simple and choice reaction time. Neuropsychologia, 15, 295-382.

Ariely, D., \& Berns, G. S. (2010). Neuromarketing: The hope and hype of neuroimaging in business. Nature Reviews Neuroscience, 11(4), 284-292. doi:10.1038/ nrn2795

Bayle, D. J., Schoendorff, B., Hénaff, M. A., \& Krolak-Salmon, P. (2011). Emotional facial expression detection in the peripheral visual field. PLoS One, 6(6), e21584. doi:10.1371/journal. pone.0021584

Beste, C., Dziobek, I., Hielscher, H., Willemssen, R., \& Falkenstein, M. (2009). Effects of stimulusresponse compatibility on inhibitory processes in Parkinson's disease. European Journal of Neuroscience, 29(4), 855-860. doi:10.1111/ j.1460-9568.2009.06621.x

Cavallet, M., Biazoli, C. E., Jr., Bazán, P. R., Chaim, T. M., Silva, M. A., Louzã, M. R., ...Busatto, G., Filho (2014, May 28). Response selection to emotional stimuli in adults with ADHD: A fMRI study using the Affective Spatial Compatibility task. Poster session presented at the $8^{\text {th }}$ Annual Canadian Neuroscience Meeting, Montreal, Canada.

Chen, S., \& Bargh, J. A. (1999). Consequences of automatic evaluation: Immediate behavior predispositions to approach or avoid the stimulus. Personality and Social Psychology Bulletin, 25(2), 215-224. doi:10.1177/0146167299025002007

Conde, E. F. Q., Jazenko, F., Fraga, R. S., Filho, da Costa, D. H., Torro-Alves, N., Cavallet, M., \& Gawryszewski, L. G. (2011). Stimulus affective valence reverses spatial compatibility effect. Psychology \& Neuroscience, 4(1), 81-87. doi:10.3922/j.psns.2011.1.010

Conde, E. Q., Cavallet, M., Torro-Alves, N., Matsushima, E. H., Fraga-Filho, R. S., Jazenko, F., Busatto, G. \& Gawryszewski, L. G. (2014). Effects of affective valence on a mixed Spatial Correspondence Task: a reply to Proctor (2013). Psychology \& Neuroscience, 7(2), 8390. doi:10.3922/j.psns.2014.021 
Eastwood, J. D., \& Smilek, D. (2005). Functional consequences of perceiving facial expressions of emotion without awareness. Consciousness and Cognition, 14(3), 565-584. doi:10.1016/j. concog.2005.01.001

Farah, M. J., Wilson, K. D., Drain, M., \& Tanaka, J. N. (1998). What is "special" about face perception? Psychological Review, 105(3), 482-498. doi:10.1037/0033-295X.105.3.482

Forstmann, B. U., Jahfari, S., Scholte, H. S., Wolfensteller, U., van den Wildenberg, W. P. M., \& Ridderinkhof, K. R. (2008). Function and structure of the right inferior frontal cortex predict individual differences in response inhibition: A model-based approach. Journal of Neuroscience, 28, 9790-9796. doi:10.1523/JNEUROSCI.1465-08.2008

Forstmann, B. U., van den Wildenberg, W. P. M., \& Ridderinkhof, K. R. (2008). Neural mechanisms, temporal dynamics, and individual differences in interference control. Journal of Cognitive Neuroscience, 20, 1854-1865. doi:10.1162/ jocn.2008.20122

Friedman, E. S., Thase, M. E., \& Wright, J. H. (2008). Cognitive and behavioral therapies. In A. Tasman, J. Kay, J. A. Lieberman, M. B. First, \& M. Maj (Eds.), Psychiatry (3 ${ }^{\text {rd }}$ ed., pp. 1920-1947). Chichester, UK: John Wiley \& Sons.

Gawryszewski, L. G., Ferreira, F. M., Martins, G., Rangel, M. L., Silva-Machado, R., Pereira, A., Jr., \& Lameira, A. P. (2008). Feixes de luz e os efeitos de compatibilidade e cruzamento. Psico PUC-RS, 39, 289-297.

Gawryszewski, L. G., Lameira, A. P., Ferreira, F. M., Silva, S. G., Conde, E. F. Q., \& Pereira, A., Jr. (2006). A compatibilidade estímulo-resposta como modelo para o estudo do comportamento motor. Psicologia USP, 17(4), 103-121. doi:10.1590/S0103-65642006000400006

De Gelder, B., Vroomen, J., Pourtois, G., \& Weiskrantz, L. (1999). Non-conscious recognition of affect in the absence of striate cortex. Neuroreport, 10, 3759-3763. doi:10.1097/00001756199912160-00007

De Houwer, J., Crombez, G., Baeyens, F., \& Hermans, D. (2001). On the generality of the affective Simon effect. Cognition and Emotion, 15, 189-206.

De Jong, R., Liang, C.-C., \& Lauber, E. (1994). Conditional and unconditional automaticity: A dual-process model of effects of spatial stimulus-response correspondence. Journal of Ex- perimental Psychology: Human Perception and Performance, 20, 731-750.

Herrmann, M. J., Biehl, S. C., Jacob, C., \& Deckert, J. (2010). Neurobiological and psychophysiological correlates of emotional dysregulation in ADHD patients. ADHD Attention Deficit Hyperactivity Disorders, 2(4), 233-239. doi:10.1007/ s12402-010-0047-6

Hommel, B. (2011). The Simon effect as tool and heuristic. Acta Psychologica, 136(2), 189-202. doi:10.1016/j.actpsy.2010.04.011

Lang, P. J., Bradley, M. M., \& Cuthbert, B. N. (2008). International affective picture system (IAPS): Affective ratings of pictures and instruction manual (Technical Report A-8). Gainesville, FL: University of Florida.

Lang, P. J., \& McTeague, L. M. (2009). The anxiety disorder spectrum: Fear imagery, physiological reactivity, and differential diagnosis. Anxiety, Stress \& Coping: An International Journal, 22(1), 5-25. doi:10.1080/10615800802478247

Leppänen, J. M., \& Hietanen, J. K. (2004). Positive facial expressions are recognized faster than negative facial expressions, but why? Psychological Research, 69(1-2), 22-29.

Lu, C. H., \& Proctor, R. W. (1995). The influence of irrelevant location information on performance: A review of the Simon and Spatial Stroop effects. Psychonomic Bulletin \& Review, 2, 174-207.

Luce, R. D. (1986). Response times: Their role in inferring elementary mental organization. New York: Oxford Science.

Markman, A. B., \& Brendl, C. M. (2005). Constraining theories of embodied cognition. Psychological Science, 16(1), 6-10. doi:10.1111/j.09562005.00772x

Matsumoto, E., Misaki, M., \& Miyauchi, S. (2004). Neural mechanisms of spatial stimulus-response compatibility: The effect of crossed-hand position. Experimental Brain Research, 158, 9-17.

Merikle, P. M., Smilek, D., \& Eastwood, J. D. (2001). Perception without awareness: Perspectives from cognitive psychology. Cognition, 79, 115-134.

Müsseler, J., Aschersleben, G., Arning, K., \& Proctor, R. W. (2009). Reversed effects of spatial compatibility in natural scenes. American Journal of Psychology, 122(3), 325-336.

Oldfield, R. C. (1971). The assessement and analysis of handness: The Edinburg Inventory. Neuropsychologia, 9, 97-113. 
Ouazzani-Touhami, Z., Benlafkih, L., Jiddane, M., Cherrah, Y., Malki, E. O., \& Benomar, A. (2011). Neuromarketing: When marketing meet neurosciences. Revue Neurologique, 167(2), 135-140. doi:10.1016/j.neurol.2010.07.025

Pellicano, A., Iani, C., Rubichi, S., Ricciardelli, P., Borghiu, A. M., \& Nicoletti, R. (2010). Real-life motor training modifies spatial performance: The advantage of being drummers. American Journal of Psychology, 123(2), 169-179.

Proctor, R. W., \& Vu, K.-P. L. (2006). Stimulusresponse compatibility principles: Data, theory, and applications. Boca Raton, FL: CRC Press.

Proctor, R. W., Yamaguchi, M., Zhang, Y., \& Vu, K.P. L. (2009). Influence of visual stimulus mode on transfer of acquired spatial associations. Journal of Experimental Psychology: Learning, Memory, and Cognition, 35(2), 434-445.

Proctor, R. W., \& Zhang, Y. (2010). "Mother nature doesn't have a bullet with your name on it": Coding with reference to one's name or object location? Journal of Experimental Social Psychology, 46, 336-343. doi:10.1016/j.jesp.2009.10.010

Proctor, R. W. (2013). Stimulus affect valence may influence mapping-rule selection but does not reverse the spatial compatibility effect: reinterpretation of Conde et al. (2011). Psychology \& Neuroscience, 6(1), 3-6. doi:10.3922/j. psns.2013.1.02

Ridderinkhof, K. R. (2002). Micro- and macro-adjustments of task set: Activation and suppression in conflict tasks. Psychological Research, $66,312-323$.

Ridderinkhof, K. R., Scheres, A., Oosterlaan, J., \& Sergeant, J. A. (2005). Delta plots in the study of individual differences: New tools reveal response inhibition deficits in $\mathrm{AD} / \mathrm{HD}$ that are eliminated by methylphenidate treatment. Journal of Abnormal Psychology, 114(2), 197-215.

Riggio, L., Gawryszewski, L. G., \& Umiltá, C. (1986). What is crossed in crossed-hand effects. Acta Psychologica, 62, 89-100.

Roth, W. T. (2005). Physiological markers for anxiety: Panic disorder and phobias. International Journal of Psychophysiology, 58, 190-198.

Rubichi, S., \& Nicoletti, R. (2006). The Simon effect and handedness: Evidence for a dominant-hand attentional bias in spatial coding. Perception \& Psychophysics, 68(7), 1059-1069. doi:10.3758/ BF03193709
Schumacher, E. H., Cole, M. W., \& D'Esposito, M. (2007). Selection and maintenance of stimulus-response rules during preparation and performance of a spatial choice-reaction task. Brain Research, 1136, 77-87. doi:10.1016/j. brainres.2006.11.081

Schumacher, E. H., \& D'Esposito, M. (2002). Neural implementation of response selection in human as revealed by localized effects of stimulusresponse compatibility on brain activation. Human Brain Mapping, 17, 193-201.

Tamietto, M., \& de Gelder, B. (2010). Neural bases of the non-conscious perception of emotional signals. Nature Reviews Neuroscience, 11, 697709. doi:10.1038/nrn2889

Umiltá, C., \& Nicoletti, R. (1990). Spatial stimulusresponse compatibility. In R. W. Proctor \& T. G. Reeve (Eds.), Stimulus-response compatibility: An integrated perspective (pp. 89-116). Amsterdam, Netherlands: Elsevier.

Usakli, A. B., Susac, A., \& Gürkan, S. (2011). Fast face recognition: Eye blink as a reliable behavioral response. Neuroscience Letters, 504(1), 49-52. doi:10.1016/j.neulet.2011.08.055

Van den Wildenberg, W. P. M., Wylie, S. A., Forstmann, B. U., Burle, B., Hasbroucq, T., \& Ridderinkhof, K. R. (2010). To head or to heed? Beyond the surface of selective action inhibition: A review. Frontiers in Human Neuroscience, 5, 1-13.

Wallace, R. J. (1971). S-R compatibility and the idea of a response code. Journal of Experimental Psychology, 88(3), 354-360.

Wylie, S. A., Ridderinkhof, K. R., Bashore, T. R., \& van den Wildenberg, W. P. (2010). The effect of Parkinson's disease on the dynamics of on-line and proactive cognitive control during action selection. Journal of Cognitive Neuroscience, 22(9), 2058-2073. doi:10.1162/jocn.2009.21326

Zhang, J., \& Kornblum, S. (1997). Distributional analyses and de Jong, Liang, and Lauber's (1994) dual-process model of the Simon effect. Journal of Experimental Psychology: Human Perception and Performance, 23, 1543-1551. doi:10.1037/0096-1523.23.5.1543

Zhang, Y., \& Proctor, R. W. (2008). Influence of intermixed emotion-relevant trials on the affective Simon effect. Experimental Psychology, 55, 431-438. doi:10.1027/1618-3169.55.6.409

Received: April, 29,2013 $1^{\text {st }}$ revision: October, 06, 2013 Accepted: January, 03, 2014 